\title{
Left ventricular assist device explant versus decommission for myocardial recovery
}

\author{
Hiroto Kitahara, MD, and Takeyoshi Ota, $\mathrm{MD}, \mathrm{PhD}$
}

\footnotetext{
From the Section of Cardiac and Thoracic Surgery, Department of Surgery, The University of Chicago, Chicago, Ill.

Disclosures: Authors have nothing to disclose with regard to commercial support.

Received for publication March 27, 2017; accepted for publication March 28, 2017; available ahead of print April $21,2017$.

Address for reprints: Takeyoshi Ota, MD, PhD, Section of Cardiac and Thoracic Surgery, Department of Surgery, The University of Chicago, 5841 S Maryland Ave, MC5040, Chicago, IL 60637 (E-mail: tota@ bsd.uchicago. edu).

J Thorac Cardiovasc Surg 2017;154:171-2

$0022-5223 / \$ 36.00$

Copyright (c) 2017 by The American Association for Thoracic Surgery

http://dx.doi.org/10.1016/j.jtcvs.2017.03.123
}

We congratulate Dracos ${ }^{1}$ on the "Expert Opinion" of myocardial recovery with mechanical circulatory support. The article provides a comprehensive summary of myocardial recovery from both current basic science and clinical practice aspects. It also includes recommendations by the National Heart, Lung, and Blood Institute Working Group with regard to scientific opportunities to be investigated for further improvement in this field, which would be helpful for scientists to brainstorm.

Myocardial recovery in patients with left ventricular assist devices (LVADs) is a known phenomenon, but only a handful of studies have been reported. ${ }^{2,3}$ Mechanical unloading of the left ventricle and intensified medical therapy induce favorable changes in the myocardium, meaning reverse cardiac remodeling. Pan and colleagues ${ }^{4}$ summarized the United Network for Organ Sharing database of the patients supported with continuous-flow LVADs and reported that $5.0 \%$ of these patients can undergo device explant for myocardial recovery. ${ }^{4}$ The predictors of myocardial recovery were detected: younger age, female sex, lower body mass index, nonischemic cause, and shorter duration of heart failure before device implantation. ${ }^{4,5}$ Although an LVAD explant would offer a better quality of life for such patients and freedom from LVAD-related complications if truly indicated, many centers have a tendency to hesitate to be aggressive in performing LVAD explants because there are no established criteria for device explant with myocardial recovery, and there are few long-term outcome data available after device explant. Birks and colleagues ${ }^{6}$ from the United Kingdom reported an acceptable long-term outcome in patients after device explant. However, caution would be necessary when interpreting their data because the myocardial recovery rate in their study was $20 \%$, which seems significantly high compared with our experience and other reports in the United States, and they might have a different patient population for initial LVAD insertion. Further studies for long-term outcomes after LVAD explant are still warranted.

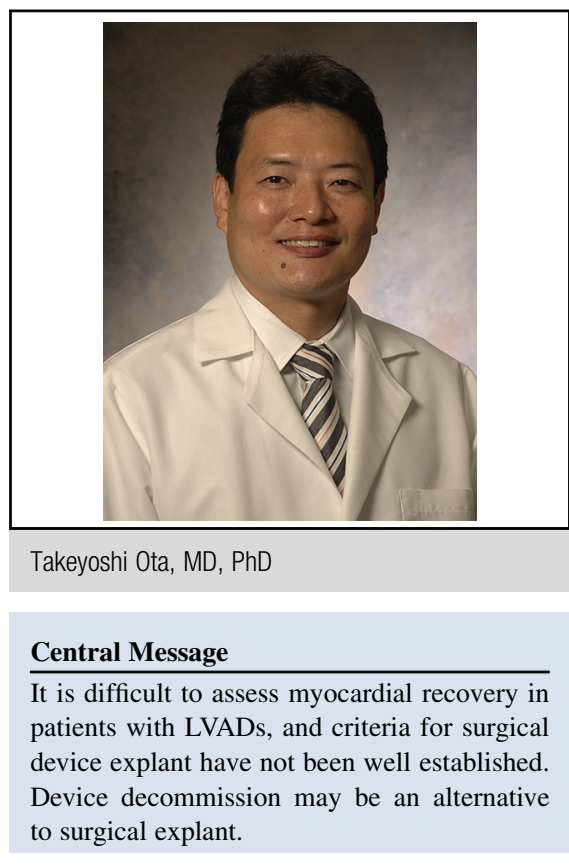

See Article page 165 .
It is reasonable, especially for surgeons, to have a hesitation to aggressively explant LVAD devices for myocardial recovery because it is generally a challenging operation to reinsert an LVAD in patients with previous explants when they relapse with heart failure requiring LVAD support. As an alternative option for myocardial recovery in patients with LVADs, device decommission has been applied in several centers. MacGowan and colleagues ${ }^{7}$ reported a minimally invasive LVAD decommission procedure in which they left the device in place, cut the driveline, and ligated the outflow graft through a small thoracotomy. Their criteria for decommission included left ventricular ejection fraction greater than $40 \%$ on computed tomography, pulmonary arterial wedge pressure less than $15 \mathrm{~mm} \mathrm{Hg}$, and cardiac index greater than $1.8 \mathrm{~mL} / \mathrm{min} / \mathrm{m}^{2}$ on low LVAD flow. In a recent effort to provide a less-invasive method, we have performed 2 LVAD decommissions for myocardial recovery using a vascular plug (Amplatzer, St Jude Medical, Inc, St Paul, Minn) to occlude the outflow graft in a percutaneous endovascular fashion as in a similarly described report by Pettit and colleagues. ${ }^{8}$ Although the device decommission procedure is less invasive, theoretically it has potential risks of infection and thromboembolic events in long-term follow-up. In addition, there are no established 
data or a strategy of anticoagulation therapy available after LVAD decommission.

Although LVAD therapy has emerged as an important strategy to treat refractory heart failure for the last decade, there are still many opportunities and questions in the queue to be investigated and answered as described in the article by Dracos. ${ }^{1}$

\section{References}

1. Drakos SG, Pagani FD, Lundberg MS, Baldwin TJ. Advancing the science of myocardial recovery with mechanical circulatory support: a working group of the National, Heart, Lung and Blood Institute. J Thorac Cardiovasc Surg. 2017; 154:165-70.

2. Levin HR, Oz MC, Chen JM, Packer M, Rose EA, Burkhoff D. Reversal of chronic ventricular dilation in patients with end-stage cardiomyopathy by prolonged mechanical unloading. Circulation. 1995;91:2717-20.
3. Burkhoff D, Klotz S, Mancini DM. LVAD-induced reverse remodeling: basic and clinical implications for myocardial recovery. J Card Fail. 2006;12: 227-39.

4. Pan S, Aksut B, Wever-Pinson OE, Rao SD, Levin AP, Garan AR, et al. Incidence and predictors of myocardial recovery on long-term left ventricular assist device support: results from the United Network for Organ Sharing database. J Heart Lung Transplant. 2015;34:1624-9.

5. Mano A, Nakatani T, Oda N, Kato T, Niwaya K, Tagusari O, et al. Which factors predict the recovery of natural heart function after insertion of a left ventricular assist system? J Heart Lung Transplant. 2008;27:869-74.

6. Birks EJ, George RS, Firouzi A, Wright G, Bahrami T, Yacoub MH, et al. Longterm outcomes of patients bridged to recovery versus patients bridged to transplantation. J Thorac Cardiovasc Surg. 2012;144:190-6.

7. MacGowan GA, Wrightson N, Robinson-Smith N, Woods S, Parry G, Gould K, et al. Myocardial recovery strategy with decommissioning for the HeartWare left ventricular assist device. ASAIO J. January 19, 2017 [Epub ahead of print].

8. Pettit SJ, Shapiro LM, Lewis C, Parameshwar JK, Tsui SS. Percutaneous withdrawal of HeartWare HVAD left ventricular assist device support. J Heart Lung Transplant. 2015;34:990-2. 